\title{
Artificial Intelligence and Information System Resilience to cope with Supply Chain Disruption
}

\author{
Shivam Gupta, Sachin Modgil, Régis Meissonierc, and Yogesh K. Dwivedi
}

\begin{abstract}
Artificial intelligence (AI) as a technology has the potential to interpret and evaluate alternatives where multidimensional data is involved in dynamic situations such as supply chain disruption. This study aims to explore the role of resilient information systems (RIS) in minimizing the risk magnitude in disruption situations in supply chain operations. The study is conducted in the qualitative mode through semi-structured interview schedule for professionals of supply chains. Thematic analysis has been used to create emerging categories. The findings of this work present critical gaps in current information systems and demonstrate how AI-oriented systems can facilitate the ecosystem of disrupted supply chains to save costs and drive efficiency on multiple parameters. The study also proposes a conceptual framework where organizational values and architectural components can be viewed jointly for quick and adequate business decisions in the complex and uncertain disruptions. The framework presents the relationships among AI, information systems and supply chain disruption. Installing appropriate AI-based data acquisition, processing and selftraining capabilities along with information system infrastructure can help organizations lessen the impact of supply chain disruption while aligning the transportation network and ensuring geographically-suitable supply chains and cybersecurity. Finally, the implications for theory and practice with the limitations and scope for future research are described.
\end{abstract}

Index Terms-Artificial Intelligence; Covid-19; Information System Resilience; Supply Chain Disruption

\section{INTRODUCTION}

Disasters are one of the key contributors to supply chain disruption [1]. For instance, General Motors was not able to run its plants in the U.S. due to its inability to source autocomponents from Japan following a tsunami in 2011; it incurred millions of dollars in losses [2], [3], [4]. In another example, the eruption of the Bardarbunga volcano in Iceland had a considerable impact on air commerce and resulted in huge revenue losses of billions of dollars [5], [6], [7].

Author(s) would like to acknowledge the comments of anonymous reviewer(s) and editor(s) for strengthening the manuscript. Corresponding author: Y. K. Dwivedi.

Shivam Gupta is with NEOMA Business School, 59 Rue Pierre Taittinger, 51100 Reims, France (e-mail: shivam.gupta@neoma-bs.fr).

Sachin Modgil is in Department of Operations Management, International Management Institute Kolkata, 2/4 C, Judges Ct Rd, Alipore, Kolkata 700027, India (e-mail:sach.modgil@gmail.com)
The worldwide supply chains are being disrupted due to Covid19 , where suppliers, distributors and manufactures have to change their strategies frequently and hence they need more information from enterprise resource planning (ERP), customer relationship management (CRM), and electronic data interchange (EDI) [8],[9]. Existing literature lack in exploring information systems as an enabler for supply chain disruptions caused due to diverse events including Covid-19 due to traditional information systems. Hence, traditional information systems may not have sufficient analytical power to make supply chains resilient [10], [13]-[20] due to their limited risk prediction and guidance towards alternatives [11], [12]. A system is defined as resilient if it quickly and efficiently guards its acute capabilities from a disruption triggered by contrary events and circumstances [36]. Due to the availability of large data, organizations are adopting AI-based technologies to address supply chain disruptions despite numerous challenges [78]. It may therefore be interesting to know how organizations are employing AI to minimize supply chain disruptions. Artificial intelligence (AI) is the intelligence demonstrated by computers and machines to perform tasks that require typical human intervention [28].

RIS can contribute significantly to the return to normal or transform the operations of a business due to a disruption as soon as possible [81]. The literature indicates the strategies around information systems and their alignment to business [74], [55]. However, the literature lack to identify the capabilities of resilient information systems that can facilitate the response to global disruptions. We therefore propose the investigation of the first research question:

RQ1. What are the capabilities of resilient information systems that help respond to global disruptions?

Information systems can be viewed as instruments that refer to a model that guides processes to transform the inputs into the outputs of a system [34], [36]. The self-organizing autonomy of information systems demonstrates the independence of

Régis Meissonier is with IAE Montpellier, Montpellier Research in Management, Monttpellier, Place Eugène Bataillon, Montpellier 34000, France (e-mail: regis.meissonier@umontpellier.fr).

Yogesh K. Dwivedi is with School of Management, Swansea University,

Bay Campus, Skewen, Swansea SA1 8EN, UK (e-mail: y.k.dwivedi@swansea.ac.uk) \& Department of Management, Symbiosis Institute of Business Management, Pune \& Symbiosis International (Deemed University), Pune, Maharashtra, India 
operations and cooperation between parties to run the business even under extreme conditions [11], [86]. To be resilient, an information system needs to be stable and in working condition, even in a dynamic environment and with regard to its relationship with other organizational elements. Existing studies lack in classifying organizational elements that can help achieve information system resilience [11], [62]. We therefore propose the second research question:

RQ2. Which organizational elements are critical to ensuring resilience in information systems?

The complexity of supply chains is visible from the complex product portfolios and their flow in the chain especially in the time of disruption [80], [81], [82]. Disruptive events expose different supply chains, be they physical or e-commerce-based [46], [70]. Disruptions ranging from natural disasters to Covid19 like pandemic create a sudden surge in demand disturbing procurement, production, logistics and distribution schedule [48], [54], [80], [86]. Recent studies emphasize the role of AI in supply chains but lack to present its role in addressing or minimizing disruptions [28], [71], [82]. We therefore propose the third research question:

RQ3. How can supply chain disruption be minimized and addressed with the help of AI?

The remainder of the paper is organized as follows: the next section presents the background of the study. Section III discusses the role of information systems and their relationship to supply chain disruptions. Section IV explains the research design. Section V presents the key findings of the study. Section VI discusses the findings of the study. To end this, we present the conclusion in section VII.

\section{BACKGROUND}

Organizations with dynamic capabilities can successfully develop, integrate, and reconfigure external and internal proficiencies and capture adequate resilience to deliver longterm performance in the era of disruption [17], [22], [23], [34]. Firms with RIS are able to sense changing customer demand patterns and customize their schedules and processes to develop the required products via real-time feedback systems through social media, newspapers, and blogs [25], [26]. Information systems can facilitate resilience in supply chains in three ways: (i) day to day supply chain operations (ii) support for network optimization and (iii) identify opportunities to deploy internet of things (IoT), blockchain, and artificial intelligence (AI) [27], [28], [29], [30], [31]. Therefore, it is important to have intelligent and flexible information systems that can facilitate discovery, recovery, and redesign of supply chain operations when a disruptive event strikes [76], [79].

\section{INFORMATION SYSTEMS RESILIENCE AND SUPPLY CHAIN DISRUPTION}

Recent disruption across the globe, ranging from natural disasters to environmental changes, Covid-19, government policy changes, cyberattacks, or tax related changes are observed [32], [33]. All of these events have a direct impact on traditional supply chains, and therefore felt the need of RIS, which in turn can help firms sense the length and breadth of the disruption to take appropriate actions [17], [21], [22]. The subsection below discusses the role of information system resilience and supply chain resilience.

\section{A. Information systems resilience}

Today, in the era of digital transactions enhanced further due to Covid-19, almost every organization is dependent on and driven by information systems that are complex and integrated with other systems [34], [35]. These systems can be relied on to provide a continuous decision support to top executives of the company and middle management along with suppliers and customers [18], [19], [20], [21]. If an interruption occurs due to technical or natural reasons such as Covid-19, then it disrupts operational activities and has cascading effects on the overall supply chain [36], [37], [38], [39].

Information systems have a significant impact on the performance of critical assets and resources of an organization along with support to innovation in situations like Covid-19 [40], [41], [42], [43]. Though interruptions like Covid-19 and natural disasters rarely occur, but the magnitude of such catastrophes can cause severe problems for supply chains and public systems.

\section{B. Era of supply chain disruption}

It has been observed that substantial disruptions in supply chains reduce the share price of affected organizations by nearly 7\% [7], [44]. In another event, recently microchip shortage have disrupted the automobile supply chain across globe. Supply chains are entering the era of disruption and facing fragile supply networks [45], [46]. Unfortunately, organizations do not bother to find the root cause of disruption unless the corollaries actually occur [47] and sometime it becomes too late to respond to a disruption that was visible in many organizations during Covid-19 [48], [49]. For instance, demand planning has collapsed dynamically in the digital shopping era, Covid-19 peak, lockdowns etc. which surpassed all the predictions concerning the purchase and consumption of products. Concurrent planning and focus on platforms, ecosystem, and customer centricity are important and critical components of an advanced supply chain strategy. Hence, AI-based modern information systems can offer better resilience to withstand supply chain disruptions.

\section{RESEARCH DESIGN}

The qualitative approach undertaken in this study proposes exposing the potential of RIS to resolve and minimize supply chain risk-related issues [46], [50]. Detailed discussion with executives from logistics and supply chain fields concerning 
various aspects of supply chain disruption and information systems were interviewed. Such research is exploratory rather than explanatory [47], [48]. A flexible approach is helpful in creating comprehension and insights into a phenomenon for which hardly any research has been conducted, hence smaller samples are recommended to generate in-depth insights [48], [49]. As per the guidelines [48], we interviewed 29 executives (masked from R1 to R29). Thematic analyses was used to classify promising subjects. The qualitative records and data helped generate themes using the inductive theory approach. Data arrays were recognized and three-layered coding used to arrive at main themes.

The respondents considered for the interview have the experience of supply chains in recent floods in the Maharashtra, Kerala, Assam, and Punjab states of India [52]. For reliability and validity of the findings, we followed an approach described by Brink and referred to the articles and industry reports indicated in Table 1 and Table 2 [74], [75], [87]. To address the issue of researcher bias we adopted, triangulation approach (Table 2) through a variety of sources that ensures the rigor and adequacy of the research findings supported by research design presented in Figure 1. In this study, we ensured reliability and validity through stability, consistency, and equivalence as suggested by Brink [87]. To ensure stability, we asked similar questions at different times to examine the consistency (the second and fourth question are intended to examine the stability of responses shown in Table 1).

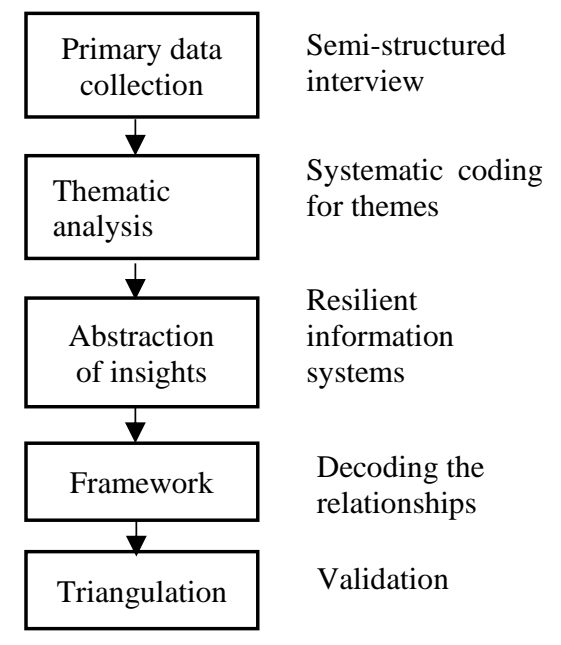

Figure 1. Steps followed for qualitative enquiry and thematic analysis

To ensure consistency, we examined the concordance of a respondent throughout the interview and presented through the views of 10th respondent. We also tested equivalence when we compared our findings with those of other researchers. Table 1 indicates the measures of reliability and Table 2 the validity through triangulation.

\begin{tabular}{|l|l|l|}
\hline Stability & Consistency & Equivalence \\
\hline Q.2 How do you & For example, & Referring to the \\
think modern & Respondent 10 & findings of [19], \\
technologies and & explained that & [36] and [85], RIS \\
information & AI can be & can offer more \\
systems can help & helpful in & flexibility, \\
tackle these & developing the & adaptability, and \\
disruptions? & best capabilities & transforming \\
Q.4 How & of an & capability for a \\
important it is to & information & supply chain in a \\
develop & system, and & disruptive \\
resilience in & also said that it & environment. \\
information & may initially & Furthermore, RIS \\
systems through & look complex & can proactively \\
artificially & and require a & help identify \\
intelligent & large & potential failure \\
technologies to & investment, but & stages and \\
prevent & could help & appropriate action \\
disruptions in the & reduce & [82]. \\
supply chain? & disruptions in & \\
& supply chains. & \\
\hline
\end{tabular}

Table 2. Validity through triangulation

\begin{tabular}{|c|c|c|}
\hline Reports & Articles & $\begin{array}{c}\text { Emerging } \\
\text { Themes }\end{array}$ \\
\hline $\begin{array}{l}\text { A report from } \\
\text { TCS [75] } \\
\text { highlights the } \\
\text { role of } \\
\text { information } \\
\text { system } \\
\text { capabilities to } \\
\text { address } \\
\text { unplanned and } \\
\text { unanticipated } \\
\text { disruptions. } \\
\text { Therefore, } \\
\text { resilient } \\
\text { information } \\
\text { systems do not } \\
\text { only offer } \\
\text { proactive } \\
\text { solutions, but } \\
\text { also facilitate } \\
\text { sharing secure } \\
\text { and relevant } \\
\text { information } \\
\text { that is timely } \\
\text { even during a } \\
\text { crisis to enable } \\
\text { further actions } \\
\text { across the } \\
\text { globe. }\end{array}$ & $\begin{array}{l}\text { System resilience } \\
\text { involves having the } \\
\text { capabilities to } \\
\text { develop the trust, } \\
\text { governance, privacy, } \\
\text { and security of the } \\
\text { supply chain. Both } \\
\text { flexible and resilient } \\
\text { elements can help } \\
\text { supply chains } \\
\text { function adequately } \\
\text { during disruption } \\
\text { [74]. The success of } \\
\text { information systems } \\
\text { depends on } \\
\text { employing data } \\
\text { acquisition } \\
\text { technologies for } \\
\text { processing and } \\
\text { learning capabilities } \\
\text { [55]. }\end{array}$ & $\begin{array}{l}\text {-Cybersecurity } \\
\text {-Data } \\
\text { acquisition } \\
\text {-Data } \\
\text { processing } \\
\text {-Geopolitical } \\
\text { information } \\
\text {-Risk } \\
\text { minimization } \\
\text {-Self learning }\end{array}$ \\
\hline
\end{tabular}

Table 1. Measures of reliability 


\section{FINDINGS}

After the interview process, the data were analyzed qualitatively to generate sub themes and main themes. These themes are explained in the following sub-sections.

\section{A. Gaps in traditional information systems}

We asked our respondents to give examples of operationallevel challenges with typical information systems referring to disruption. The issues raised by our respondents are described below.

\section{1) Handling of multi-dimensional data with speed and accuracy}

Respondents indicated that at times it becomes difficult to get information on time to process and make decisions to avoid the impact of disruption. The data are generated in the form of emails, phone calls, audio, video, networks and maps of the supply chain. As Respondent R23 (Senior Manager from the FMCG sector) noted, "in disruptive events, we have a multitude of data coming from the internet, print media and our suppliers, customers and other social media platforms in different forms ranging from images of floods/fires/lockdowns of affected areas to videos and phone conversations and it becomes extremely difficult for us to combine all the data for accurate and fast decisions. Additionally, it reduces the efficiency of our supply chain and poses challenges to business continuity". Therefore, the handling of multidimensional data not only affects the productivity of supply chains, but also costs firms in terms of reducing service levels and the availability of necessary products in affected areas.

\section{2) Lack of insight generation}

Built-in, pre-defined boundaries drive traditional system operations. It was pointed out by the respondents that the existing systems play an important role in day-to-day, routine supply chain operations, but not enough for disruption scenarios. As Respondent R27 (Vice President in the logistics and supply chain field) noted, "the mission of our business has been redefined to meet the current challenges of supply chain disruption through our information systems, where we are employing machine learning and AI-based algorithms to detect, respond and recover early on". Our respondents explained that there had been instances when they required information that was not a part of the existing system and database, and due to central bias, these types of scenarios are ignored by traditional information systems [54], [78].

\section{B. Dynamic decision-making capability}

The role of information becomes critical in the decisionmaking process during supply chain disruption [84]. Hence, the RIS can play a key role in mitigating the risk involved in disruption events.

\section{1) Integration of physical operations and computing}

\section{characteristics}

Supply chains typically run through the physical network, where the movement of goods becomes a challenge when disruptions occur. In this regard, Respondent R9 (Manufacturing and Supply Chain Director in the FMCG domain in a conglomerate) noted that, "the design of our distribution network and its seamless integration with our information system and its flexibility in providing access to system data, components, and external assets helps us to be aware of any potential vulnerabilities early on". On similar lines, Respondent R24 (Supply Chain Director from a confectionary firm) noted that, "digital twin-like simulation models can help our supply chain planners experiment with disruption scenarios and their impact on the physical supply chain to safeguard against the disruption impact".

\section{2) Self-learning mechanisms}

Our respondents highly recommended the utilization of learning and logical reasoning competencies of modern technologies such as AI, big data analytics, IoT, blockchain and machine learning. These technologies can assist firms in collating unstructured data and making decisions in uncertain environments [59]. In this regard, Respondent R26 (Senior Manager from the personal care field in the FMCG industry handling supply chains) noted that, "Geomaps-based location tracking and causes of supply disruption can be identified through blockchain, whereas AI and machine learning can help recognize demand and supply". In case of emergency, advanced information systems can play a significant role in terms of resources and asset allocation.

\section{Cooperation among stakeholders towards resilience}

Modern information systems can help rebuild trust and capture market share by choosing more accurate forecasts and appropriate modes of supply with the help of different stakeholders. However, our respondents indicated that many supply chains lack the desired characteristics for resilience based on the support of information systems.

\section{1) Lack of process maturity across the value chain}

Supply chain network success depends on the maturity of informed supply chain nodes to ensure visibility and demand on a collaborative basis. Respondent R14 (Purchasing Manager from an electrical equipment company) noted that, "value chain stakeholders should consider appropriate elements for supply chain integration and extension with $\mathrm{AI}$ technologies to bring end-to-end visibility. For instance, with the rising need for customization, there are multiple stock keeping units (SKUs), so to account for large amounts of data, too many applications and various intelligent systems are required". The success of any supply chain in a disrupted environment depends on what needs to be achieved in the situation. Therefore, it is important for all partners to define and adhere to the common objectives 
of the value chain.

\section{2) Lack of trained workforce}

To handle data driven environment, firms require dataliterate professionals who can interpret data and make decisions quickly [72]. In this regard, Respondent R18 (Vice president in a retail company) noted that "today's firms are looking for data science talent and AI professionals to stand out from the crowd, whereas organizations are not training their workforce on recent technologies; instead they prefer to hire externally". Hiring the right person has been always a challenge for companies seeking to meet certain expectations.

\section{Information system resilience as the basis for a firm's orientation}

The appropriate degree of resilience in information systems helps firms recover quickly, maintain the customer base and develop a growth orientation. Our respondents indicated how they view the RIS and their fit in the firm's strategy.

\section{1) Potential support for strategic assessments}

Today, information systems are designed with room to extend and enhance multi-dimensional capabilities in the future, if required. Our Respondent R28 (Manufacturing Director in an FMCG company) noted that "the design of information systems both from soft and hard perspectives is being considered to maximize risk intelligence and to have a long-term effect, through characteristics of sensing, comprehending, acting and learning, where in learning, approaches from deep learning to genetic programming can be adopted. This strategic orientation can be infused with modern information systems with the help of interconnected devices.

\section{2) Potential support for operational assessments}

The information systems decode and analyze the data of company operations and present them to the decision maker to make the final call. Our Respondent R13 (Senior Executive from the Food \& Beverage Industry) noted that "an information system can evaluate and forecast figures on the basis of current expenses, workforce, manufacturing activities, and sales. For instance, with the recent floods in the region, our information systems indicated an approximate production figure with $95 \%$ confidence to divert and plan manufacturing activities, which has further helped us to make changes in our supply chain". The decisions depend on the data and assumptions made during analysis by information systems. Modern information systems can help make decisions when multiple options are available.

\section{3) Opportunity to restore customer loyalty}

In the recent past, there have been numerous catastrophic events including Covid-19 that have caused serious disruptions in the supply chain and attracted the attention of firms to refine the recovery strategies. Our Respondent R15 (Purchasing Manager from an FMCG company) noted that "disruption retrieval processes affect value chain relationships through the level of accessibility, ethical behavior, and sensitivity towards the delivery of goods to affected areas, and AI-driven systems can employ natural language processing to deliver goods to the exact location and customers". If a supply chain fails or slows down, then customer satisfaction is at risk and an opportunity can be lost.

\section{E. Enriching the capability of AI for RIS}

AI uses the computer network to simulate human intelligence and collect data from sensors to make appropriate decisions.

\section{1) AI learning from other disciplines}

AI is being used today in the form of automatic programming, neural networks, natural language processing and predicting market competition with case-based reasoning. Our Respondent R3 (Supply Chain Senior Executive from a business services company) noted that "AI can be used to detect fraud in a business and can help improve customer relationship management with a rule-based approach, where intelligent systems can make use of interdepartmental and external information to find gaps". AI can also use Bayesian networks and machine-learning techniques to detect fraud. As indicated earlier, AI simulates human intelligence and can learn from other disciplines.

\section{2) Human interface}

The analytical capability of AI and psychological and emotional elements of practitioners can be combined to make more accurate decisions. Our Respondent R16 (Logistics and Supply Chain Manager in the oil and gas sector) noted that "AI assists firms in creating products and services by helping remove their focus from data and the difficulty of drawing insights from big and different types of data". Supply chain disruption and other firm operations generate multi-format data that may be extremely difficult for a working executive to manage.

\section{F. Challenges of AI with regard to RIS}

The impact on labour and control of complex systems is a challenge that AI poses for today's information systems. Certain on-site adoption challenges are delineated in the subsections below.

\section{1) Non-inclusion of experience of senior managers}

AI does not include their experience and emotional quotient in decision making and predicting the scenarios. Our Respondent R26 (Supply Chain Senior Manager from the FMCG industry) noted that "the action of top management shapes the behavior and interaction among employees, whereas AI may not have that capability of affecting the behavioral 
characteristics in the organization, on the supplier side or even the customer side". The experience of customers and practicing executives at firms is of the utmost importance and plays a significant role in strategic decisions.

\section{2) High initial investment}

Many cloud-based services require greater AI infrastructure and a huge investment. Investment in AI is multi-dimensional. Our Respondent R10 (Senior Manager in a third-party logistics company) noted that "AI being in its initial stages of implementation, there is a shortage of AI researchers and programmers that can design customized supply chain solutions". Certain industries such as the pharmaceutical industry require heavy investment and the probability of the return on investment is usually low. AI can enhance the efficiency of manufacturing via digital twins that can recognize movements and anomalies for better prediction. In addition to this, it has also been noted that the integration of functions and values into $\mathrm{AI}$ is a challenge.

\section{3) Fear of not acclimatizing to new technologies}

Many organizations are training their workforce with the help of consultants to utilize AI systems, but many firms want to substitute them with new, young people who are good at programming and extracting insights. Our Respondent R21 (Demand Planning Manager from a consumer healthcare firm) noted that "companies today are looking for the right combination of talent, who can perform managerial as well as technical tasks to accelerate the value chain and strengthen the resilience of their information systems and understand the technical know-how of the value chain". Many organizations are living in fear that they may not be able to adapt to new technologies such as AI and they want others to experiment first to see the results of adoption.

\section{DISCUSSION}

Information systems cannot work in isolation and require a holistic approach to develop, maintain, and enhance the resilience of information systems to combat unforeseen disruptions [14]. The traditional systems have a narrow scope of resilience due to their limited analytical capabilities [36]. The current generation of rapid and multi-dimensional data poses a challenge to the existing systems to drive value chain operations and have a direct or indirect impact on the firm's performance [56], [57], [58]. The findings also indicate that AIsupported information systems can help firms restore customer loyalty and attract new customers when accurate data collection and filtration processes are in place across multiple locations around global supply chains. This filtered data can further act as a dynamic capability of producing more useful insights for different geographical locations, though it requires a high initial investment. This answers the first research question.
Though predictive analytics and other approaches like big data analytics offer a range of data handling competencies, the information systems exceed their functionalities in terms of interpretation, the extent of data and the type of data processing to determine logical solutions [59], [60]. When responding to a disruption scenario, the systems need to be fast, accurate and holistic. Therefore, information systems coupled with an appropriate degree of intelligence can pave the way to tackle supply chain disruptions with sufficient resilience [41]. The present state of information systems can facilitate strategic planning with an accurate forecasting vision, whereas AIenabled information systems have the potential to uncover other areas that can help lower the risk of disruption along with other applications that are unexplored in the pre-Covid era [12]. The degree of resilience of the information systems will define the analytical capacity of the system, even in worst case disruption scenarios [62], [63]. Therefore, we find that RIS dictate the orientation of firms so that they are committed to the exploration of new and innovative solutions via integration of different value chain elements [64]. This answers the second research question. Being differently focused organizations, they can still pursue a collective vision of integrating the information systems [59], [61]. This therefore leads towards an all-inclusive analysis of information and can offer intelligent and innovative solutions during disrupted events in the value chain.

The analytical capabilities of resilient systems offer working executives room to focus more on implicit business and supply chain aspects, such as employee training and building trust among customers and stakeholders during disruption situations such as Covid-19 [49]. The results of the study led us to develop a conceptual framework presented in Figure 2 indicating the sequence of information acquisition, analysis, and interpretation in a supply chain disruption scenario with the help of RIS and have two perspectives (i) RIS are capable of data acquisition and self-learning and (ii) organize itself to match to vision of the organization for supply chain [36], [65], [66]. Additionally, potential of joint action with the experience of professionals and the analytical capabilities of AI offers an ideal solution to minimize the risk of huge losses during the disruption. This answers the third research question. In this way, AI can facilitate modern information systems to offer resilience at the system level and drive agility if disruption strikes.

\section{A. Implications for theory}

AI-based information systems have the potential to cope with increasing complexity in the supply chain environment and specifically during unpredictable events. The present study highlights key problems and challenges with respect to the contextual problems of resuming operations, analyzing impact and designing a strategy to recover faster from supply chain disruption. It offers an opportunity for researchers and practitioners who are working in the field of resilience and supply chain disruption and who consider AI and information systems to be an integral part of this. This leads us to further explore methods for using technologies such as AI and its 
integration with other technologies as a strategic front against any kind of disruptions [29]. The resilience of information systems ensures the sustainable growth of a supply chain [36]. As AI is in its initial phases, in order to minimize and predict the degree of supply chain disruption such as Covid-19, the present study contributes by providing the experience of industry people in terms of issues and challenges for AIinduced information systems [39]. Additionally, the unique application of AI systems for the development of resilience and in turn the reduction of supply chain risk is explored. This study contributes to dynamic capabilities and organizational preparedness literature in terms of its observed and potential benefits with the help of emerging technologies. Based on the statements of the respondents, it is also clear that AI-supported information systems have considerable potential for systemic integration with other platforms to become closer to reality [68]. It therefore develops an understanding of how AI-devised information systems can ensure resilience and further help firms design operations in view of a probable disruption [69]. The present study presents the implications for scholars of information systems, supply chain operations and humanitarian logistics. From the capability studies view, it indicate the potential how the unique capabilities of AI can be built and exploited when needed to serve the end consumer in extreme and complex situations such as Covid-19. In addition, it advances the understanding on role of organizational information processing theory in collaborative decision making quickly [70].

Data acquisition is a first step towards data quality management, whereas AI helps in identifying the right sources and putting the right technologies in place [15]. After the adequate data acquisition, analysis is performed quickly with algorithmic capabilities and data processing technologies that help identify pattern recognition and useful insights with largescale heterogeneous data [30], [31]. In summary, an advanced information system architecture is flexible and agile and can facilitate quick allocation of resources to respond to disruptive environments. Due to continuous monitoring and adaptation capabilities, modern information systems must be selforganized and able to handle multi-objective data to reduce supply chain disruptions. These points led us to the first proposition:

P1: Artificial intelligence facilitates the robustness and flexibility of modern information systems that are capable of quick data acquisition and processing along with training itself based on data patterns for better decision making and reduced disruption impact.

A resilient information system can contribute towards the objective of an organization, even in complex and highly uncertain situations such as Covid-19. A resilient information system meets requirements such as availability, interoperability, security, reliability, safety, robustness, and usability [6]. Any deficiency in these characteristics can lead to a disruptive impact and compromise the system. Modern information systems should resist any kind of adversity and offer continuous support in degraded mode, despite disturbance and emergency situations [7]. Resilient information systems are capable of recovering quickly from the destruction that the disruption may have caused and still be able to model different operations options to service the supply chains in complex environment as Covid-19, natural disasters and political instability [36]. To develop resilient information systems, one needs to ask what kind of capabilities should be developed so that the system can continue to provide them during and after the disruption. What could the outcome of the disruption be? What kind of adversity could interrupt the maintenance of critical capabilities? Addressing these concerns appropriately in information systems can provide the necessary resilience at different supply chain nodes via timely execution and deployment. This further helps in reducing supply chain risk and keeping functions running those are critical for situation like Covid-19. In summary, resilient information systems can help supply chains to manage crises in difficult times such as the Covid-19 pandemic, where supply chains are at higher risk. Therefore, along with the self-training capabilities of AI-based information systems, it is critical that information systems offer alternative scenario planning and strategic execution to minimize supply chains risks in disruptive environments. These highlights lead us to the second proposition:

P2: Resilient information systems help supply chains with better modeling options and significantly reduce risk when executing supply chain operations.

A disaster whether it is natural disaster or Covid-19 or semiconductor chip shortage like situation, it causes extensive damage to people, networks, and physical infrastructure that is invisible to many people, even in the organization, in terms of scale and extent. That means that different sources of possible disruption have not been appropriately evaluated, resulting in minimal preparation [62]. One important area for supply chains is the transportation network. The transportation network is a critical component in the supply chain, since it connects different stakeholders such as suppliers, distributors, and customers [12]. Transportation enables the movement of the right kinds of raw materials, semi-finished, and finished products towards the customer and is critical in the disruptive environment such as Covid-19. Therefore, an upstream and downstream balance in geographic status can help supply chains maintain a suitable cycle time. Over the last two decades, supply chains have been oriented towards digitization, where access to information is convenient for all stakeholders. With this convenience, the safety and security of information risks being compromised, leaving supply chain data exposed to a possible disruption. Due to Covid-19, many supply chains go digital and confidential information is at risk [47], creating threats in terms of cyber risk, counterfeit parts, and supply chain ethics leading to supply chain disruptions [67]. A Covid-19impacted supply chain represents uncertainty and changes in consumer preferences that can be further influenced by cultural 
elements of organization reflected in the supply chain. In summary, the geographical and geopolitical aspects of supply chains have been highlighted both at the global and regional level. The impact of a disruption can be felt more strongly due to poor transportation networks, weak cybersecurity and staggered business culture. Hence, to prepare for supply chains disruption, firms need to align their information systems across functions. These points lead us to the third proposition:

P3: A better understanding of geopolitical status, the degree of cybersecurity requirements, the transportation network, and business ethics can help reduce the impact of supply chain disruption. Modern and resilient information systems can help reduce this impact significantly.

The proposed model in Figure 2 indicates the crucial elements of AI-sustained information systems for handling the supply chain. Though the adoption of AI in the disruptive business environment is quite recent, the findings suggest that AI can be explored by managers to design and develop RIS for complex situations.

\section{B. Implications for practice}

AI-based systems have the ability to extract required information from different sources and apply suitable algorithms to explore a novel avenue for a specific supply chain disruption scenario. The study offers exclusive implications for working executives, since it provides a comprehensive framework for connecting the architectural and conceptual elements of supply chain operations. This framework also indicates the potential role it can play in offering practical insights. The applications of AI are evolving, and the insights of this study can help firms design their strategies to tackle complex business issues such as supplying products and services during and after a disruption incident of complexity such as semiconductor chip shortage or Covid-19. The investment orientation of a firm towards AI can impact the strategic and operational decisions and ultimately the performance of a business. This impact of AI in terms of supply chain performance can act as a basis for working executives to consider the shift towards more resilient and intelligent systems [71]. The present study offers managers and working staff an understanding of how AI-oriented information systems are helpful for their supply chain operations in an increasing complex and uncertain environment. The study highlighted the different capabilities of these systems and their contribution towards restoring trust between customers and the supply chain during and after disruption. Hence such systems can be utilized to simplify and manage the available knowledge and information to make informed decisions. Professionals from the engineering and management fields can come together to create more capabilities such as cyber-resilience, that can help with quick responses to risks and disruptions, especially for digitally-operated business activities. In global and complex networks, the management and technical teams should focus on interoperability, due to the different types of information technology interfaces in different countries. Hence, professionals (from developers to users) should work to ensure the easy connection and collection of information from varied sources, such as the customs administration, trade documentation, and dissemination of real-time information among stakeholders. The executives in information systems and supply chains can work on utilizing the synergies of both to achieve ambidexterity in operations. Ambidexterity will promote the exploitation of current infrastructure while deploying AI-based systems to advance its role during disruptive supply chain scenarios.

The involvement of executives in adopting AI systems can be ensured once they are aware of how and to what extent it can augment their decision making and what degree of complexity is considered now learned from Covid-19 [72]. This study offers useful assistance to professionals who are working in designing and implementing AI systems in firms to ensure uninterrupted supply in every situation and to manage the supplier and customer sides of the supply chain. Apart from suppliers and customers, information systems are critical for the adequate allocation and utilization of resources such as raw materials and equipment and hence require resilience through technologies such as AI to address the uncertain situations such as semiconductor chip shortage or Covid-19. AI-based systems can detect signals towards any abnormal behavior that may lead to an unprecedented scenario. Data-oriented platforms and systems exhibit behavior that is helpful in solving problems, discovering new knowledge and manipulating supply chain data when needed for quick and precise decision making in situations like blockage of Suez Canal. Nevertheless, the firms in a developing country like India have a long way to go to develop a robust and sustainable AI infrastructure for supply chain. Infrastructure facilitation and support need to be in place before starting any AI adoption and implementation. Therefore, chief information officers (CIOs) and top management along with practicing managers need to design AI systems to improve productivity in each scenario. A final important implication of this study is the inevitability of AI adoption and the involvement of the programmer and developer during designing in order to pay attention to critical components of the supply chain network and existing infrastructure that need close coordination between developer and user. If organizations aim to reduce the impact of disasters and other disruptive events including Covid-19, then it is necessary to conceptualize, design, and develop systems that are capable of learning, reasoning, and performing tasks similar to humans with more speed and quicker recovery to transform supply chains. The lessons from different disruptions (Covid-19, Suez Canal or Semiconductor chip shortage) can be considered to develop the resilient information systems.

\section{Limitations and scope for future research}

In this study, we adopted a conceptual and exploratory 
IEEE TRANSACTIONS ON ENGINEERING MANAGEMENT

approach. The study offers a more contextual scenario since most of the respondents were from the manufacturing sector. The support of empirical research is necessary to generalize the results. Supply chain disruptions present a rich background for the design and development of AI-based systems to develop resilience. However, the present study involved a single respondent per firm and similar designations at different organizations. Future research can consider other aspects of the functional view of the organization, such as finance (measuring market sentiments, investment decisions), marketing (consumer sentiments and requirements for new product development), and production (scheduling and maintenance). This type of research could also observe the level of adoption at the firm and individual level. The correct adoption and implementation approach can be further supported with largescale empirical studies. Such research can be based on the involvement of multiple variables in the adoption and implementation of AI systems for supply chain operations.

\section{CONCLUSION}

Our study investigates the role of resilient information systems in reducing the risk of disruption in the supply chain. We have gathered the data through a semi-structured approach of interviews and transcribed them into main content to further analyze them. We used the thematic analysis approach, where we first identified the gaps in the traditional information systems leading to how AI can help develop a strong architecture of resilient information systems. Furthermore, we identified the challenges of $\mathrm{AI}$ in achieving resilient information systems. Our study proposes how AI elements can offer an ecosystem support to modern and resilient information systems. Our study provides a framework, where architectural components used together can help reduce supply chain disruptions and prepare it for dynamic scenarios. 


\section{APPENDIX}

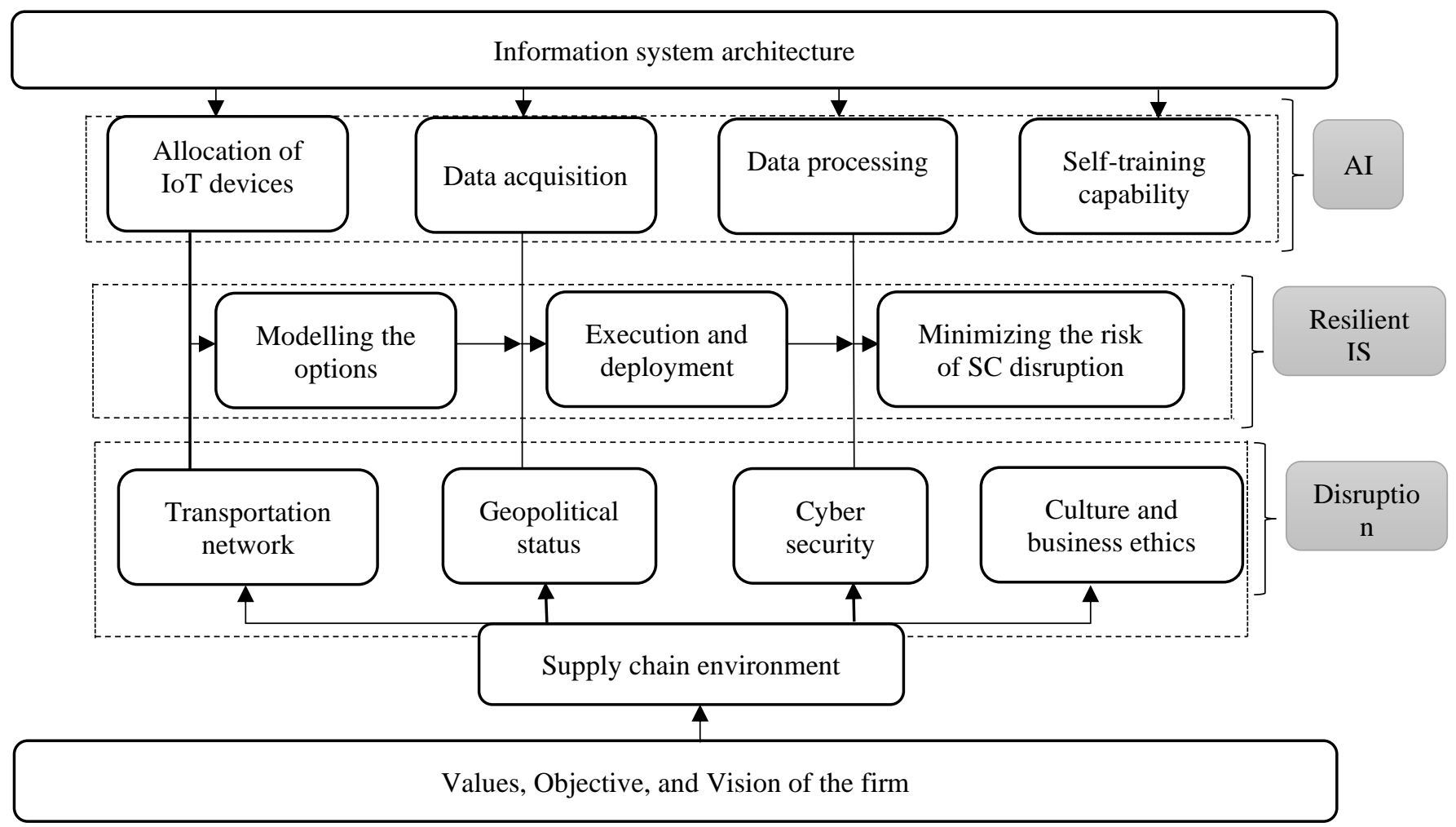

Figure 2 Conceptual framework to ensure IS resilience to overcome SC disruption 


\section{REFERENCES}

[1] R. Diaz, J. G. Behr, F. Longo, and A. Padovano, "Supply Chain Modeling in the Aftermath of a Disaster: A System Dynamics Approach in Housing Recovery," IEEE Transactions on Engineering Management, vol. 67, no.3, pp. 531-544, Dec. 2019.

[2] S. Hosseini, D. Ivanov, and A. Dolgui, "Review of quantitative methods for supply chain resilience analysis," Transportation Research Part E: Logistics and Transportation Review, vol. 125, pp. 285-307, May. 2019.

[3] M. Haraguchi, and U. Lall, "Flood risks and impacts: A case study of Thailand's floods in 2011 and research questions for supply chain decision making," International Journal of Disaster Risk Reduction, vol. 14, pp. 256-272, Dec. 2015.

[4] A. Herod" "What does the 2011 Japanese tsunami tell us about the nature of the global economy?," Social \& Cultural Geography, vol.12, no. 8, pp. 829837, Nov. 2011.

[5] M. Dirscherl, and C. Rossi, "Geomorphometric analysis of the 2014-2015 Bárðarbunga volcanic eruption, Iceland," Remote Sensing of Environment," vol. 204, pp. 244-259, Jan.2018.

[6] R. Dubey, A. Gunasekaran, S. J. Childe, S. Fosso.Wamba, D. Roubaud and C. Foropon, "Empirical investigation of data analytics capability and organizational flexibility as complements to supply chain resilience," International Journal of Production Research, vol.59, no. 1,pp. 110-128. Feb.2019.

[7] Z. Chen, J. Li, Z. Liu and Z. Zheng, "Incentive contracts for capacity restoration under risk of supply disruption," IEEE Transactions on Engineering Management, vol.66, no. 4, pp. 746762. July. 2018.

[8] A. Gunasekaran, K.H. Lai and T.E. Cheng, "Responsive supply chain: A competitive strategy in a networked economy," Omega, vol. 36, no. 4, pp. 549-564, August. 2008.

[9] M. Gupta and A. Kohli, "Enterprise resource planning systems and its implications for operations function," Technovation, vol. 26, no. 5-6, pp. 687696, May-June. 2006.

[10] J. Sarkis, and S. Talluri, "Editorial design and management of sustainable and resilient supply chains," IEEE Transactions on Engineering Management, vol. 66, no. 1, pp. 2-7, Jan.2019.

[11] J.L. Spears, and H. Barki, "User participation in information systems security risk management," MIS Quarterly, vol.34, no.3, pp.503-522, Sep. 2010.

[12] O. Akinrolabu, J.R. Nurse, A. Martin, and S. New,
"Cyber risk assessment in cloud provider environments: Current models and future needs," Computers \& Security., to be published. DOI: 10.1016/j.cose.2019.101600.

[13]R. El-Haddadeh, "Digital Innovation Dynamics Influence on Organisational Adoption: The Case of Cloud Computing Services," Information Systems Frontiers, vol. 22, no.4, pp. 985-999, April. 2019.

[14]E.Atalay, P. Phongthiengtham, S. Sotelo, and D. Tannenbaum, "New technologies and the labor market," Journal of Monetary Economics, vol. 97, pp. 48-67, August. 2018.

[15] K. Govindan, T.C.E.Cheng, N.Mishra and N. Shukla, "Big data analytics and application for logistics and supply chain management," Transportation Research Part E: Logistics and Transportation Review, vol.114, pp. 343-349, June. 2018.

[16] A. Jabbarzadeh, B. Fahimnia, and S. Rastegar, "Green and resilient design of electricity supply chain networks: a multiobjective robust optimization approach," IEEE Transactions on Engineering Management, vol. 66, no. 1, pp.52-72, October. 2017.

[17] D.J. Teece, G. Pisano, and A. Shuen, "Dynamic capabilities and strategic management," Strategic Management Journal, vol.18, no. 7, pp. 509-533, Aug. 1997.

[18] G. Bhatt, A. Emdad, N. Roberts, and V. Grover, "Building and leveraging information in dynamic environments: The role of IT infrastructure flexibility as enabler of organizational responsiveness and competitive advantage," Information \& Management, vol.47, no.7-8, pp. 341-349, Dec. 2014.

[19] J. Zhang, H. Li, and J.L. Ziegelmayer, "Resource or capability? A dissection of SMEs' IT infrastructure flexibility and its relationship with IT responsiveness," Journal of Computer Information Systems, vol.50, no.1, pp. 46-53, Sep. 2009.

[20] G. Ray, W.A. Muhanna, and J.B Barney, "Information technology and the performance of the customer service process: A resource-based analysis," MIS Quarterly, vol. 29, no. 4, pp.625652, Dec. 2005.

[21] J.H. Dyer, and H. Singh, "The relational view: Cooperative strategy and sources of interorganizational competitive advantage," Academy of Management Review, vol. 23, no.4, pp. 660-679, Oct. 1998.

[22] D.J. Teece, "Explicating dynamic capabilities: the nature and microfoundations of (sustainable) enterprise performance," Strategic Management Journal, vol.28, no.13, pp.1319-1350, Dec. 2007.

[23] L.Y. Wu, "Applicability of the resource-based and dynamic-capability views under environmental 
volatility," Journal of Business Research, vol. 63, no.1, pp. 27-31, Jan. 2010.

[24] R. Agarwal, and W. Selen, "Dynamic capability building in service value networks for achieving service innovation," Decision Sciences, vol. 40, no.3,pp. 431-475, Aug. 2009.

[25] S. Gosain, A.Malhotra, and O.A El Sawy, "Coordinating for flexibility in e-business supply chains," Journal of Management Information Systems, vol. 21, no.3, pp.7-45, Nov. 2004.

[26] A.A Bush, A. Tiwana, and A. Rai, "Complementarities between product design modularity and IT infrastructure flexibility in ITenabled supply chains," IEEE Transactions on Engineering Management, vol. 57, no.2, pp. 240254, Feb. 2010.

[27] J. Lee, B. Bagheri, and H.A. Kao, "A cyber-physical systems architecture for industry 4.0-based manufacturing systems," Manufacturing Letters, vol.3, pp.18-23, Jan. 2015.

[28] Y. K. Dwivedi, L. Hughes, E. Ismagilova, G. Aarts, C. Coombs, T.Crick,... and, V. Galanos, "Artificial Intelligence (AI): Multidisciplinary perspectives on emerging challenges, opportunities, and agenda for research, practice and policy," International Journal of Information Management., vol. 57, pp. 101994, April. 2021.

[29] M.M. Queiroz, and S.F Wamba, "Blockchain adoption challenges in supply chain: An empirical investigation of the main drivers in India and the USA," International Journal of Information Management, vol. 46, pp. 70-82, June. 2019.

[30]R. Dubey, A. Gunasekaran, S.J. Childe, D. Roubaud, S.F. Wamba, M. Giannakis, and C. Foropon, "Big data analytics and organizational culture as complements to swift trust and collaborative performance in the humanitarian supply chain," International Journal of Production Economics, vol. 210, pp.120-136, April. 2019.

[31] T. Papadopoulos, A. Gunasekaran, R. Dubey, N. Altay, S.J. Childe, and S.F. Wamba, "The role of Big Data in explaining disaster resilience in supply chains for sustainability," Journal of Cleaner Production, vol. 142, pp. 1108-1118, Jan. 2017.

[32] E. Krausmann, S. Girgin, and A. Necci, "Natural hazard impacts on industry and critical infrastructure: Natech risk drivers and risk management performance indicators," International Journal of Disaster Risk Reduction., to be published. DOI: 10.1016/j.ijdrr.2019.101163

[33] R. Hemingway, and O. Gunawan, "The Natural Hazards Partnership: A public-sector collaboration across the UK for natural hazard disaster risk reduction," International Journal of Disaster Risk Reduction, vol. 27, pp.499-511, March. 2018.

[34] P.D.C, Fiorini, C. J. C. Jabbour, A. B. L. de Sousa
Jabbour, N.O. Stefanelli, and Y. Fernando, "Interplay between information systems and environmental management in ISO 14001-certified companies," Management Decision, vol. 57, no.8, pp. 1883-1901, Sep. 2019.

[35] R. Santhanam, and E. Hartono, "Issues in linking information technology capability to firm performance," MIS Quarterly, vol. 27, no.1, pp. 125-153, March.2003.

[36] R. Heeks, and A.V. Ospina, "Conceptualising the link between information systems and resilience: A developing country field study," Information Systems Journal, vol. 29, no.1, pp. 70-96, Jan. 2019.

[37] A. Dolgui, D.Ivanov, S. Setho, and B. Sokolov, "Control theory applications to operations systems, supply chain management and industry 4.0 networks," IFAC-PapersOnLine, vol. 51, no. 11, pp. 1536-1541, Jan.2018.

[38] C.S. Singh, G.Soni, and G.K. Badhotiya, "Performance indicators for supply chain resilience: review and conceptual framework," Journal of Industrial Engineering International, vol.15, no.1, pp. 105-117, Dec. 2019.

[39] D.D. Wu, S.H. Chen, and D.L. Olson, "Business intelligence in risk management: Some recent progresses," Information Sciences, vol. 256, 1-7, Jan. 2014.

[40] U. Sivarajah, M.M. Kamal, Z. Irani, and V. Weerakkody, "Critical analysis of Big Data challenges and analytical methods," Journal of Business Research, vol.70, pp.263-286, Jan. 2017.

[41] L. Zhou, X. Wu, Z. Xu, and H. Fujita, "Emergency decision making for natural disasters: An overview," International Journal of Disaster Risk Reduction, vol. 27, pp. 567-576, March. 2018.

[42] I.A Tøndel, J. Foros, S.S. Kilskar, P. Hokstad, and M.G. Jaatun, "Interdependencies and reliability in the combined ICT and power system: An overview of current research," Applied Computing and Informatics, vol.14 no.1, pp. 17-27, Jan. 2018.

[43] Eusgeld, C. Nan, and S. Dietz, “'“System-ofsystems" approach for interdependent critical infrastructures," Reliability Engineering \& System Safety, vol. 96, no.6, pp.679-686, June. 2011.

[44] Culp, "Supply chain disruption a major threat to business," July. 13, 2019. [Online]. Available : https://www.forbes.com/sites/steveculp/2013/02/1 5/supply-chain-disruption-a-major-threat-tobusiness/\#3140f98f73b6

[45]Y. Wang, and J. Wang, "Measuring and Maximizing Resilience of Transportation Systems for Emergency Evacuation," IEEE Transactions on Engineering Management, vol. 67, no.3, pp.603613, Nov. 2019.

[46] R. Mogre, S. Talluri, and F. D'Amico, “A decision framework to mitigate supply chain risks: an 
application in the offshore-wind industry," IEEE Transactions on Engineering Management, vol. 63, no.3, pp. 316-325, June .2016.

[47] M. Pagell, and $\mathrm{Z}$. Wu, "Building a more complete theory of sustainable supply chain management using case studies of 10 exemplars," Journal of Supply Chain Management, vol. 45, no.2, pp. 3756, April. 2009.

[48] M. Crouch, and H. McKenzie, "The logic of small samples in interview-based qualitative research," Social Science Information, vol. 45, no.4, pp. 483499, Dec. 2006.

[49] S. Kaur, S. Gupta, S.K. Singh, and M. Perano, "Organizational ambidexterity through global strategic partnerships: A cognitive computing perspective," Technological Forecasting and Social Change, vol.145, pp. 43-54, Aug. 2019.

[50] O.C. Robinson, "Sampling in interview-based qualitative research: A theoretical and practical guide," Qualitative Research in Psychology, vol. 11, no. 1, pp. 25-41, Jan. 2014.

[51] G. Guest, A. Bunce, and L. Johnson, "How many interviews are enough? An experiment with data saturation and variability," Field Methods, vol. 18, no.1, pp. 59-82, Feb. 2006.

[52] Reliefweb, "Situation report on Flood/Heavy Rain fall in Maharashtra, Kerala, Karnataka, Gujarat, Assam, Bihar, Oisha, West Bengal, Madhya Pradesh, Rajasthan and Punjab as on 18th August 2019 at 1800 Hrs. September. 5, 2019. [Online]. Available https://reliefweb.int/report/india/situation-reportfloodheavy-rain-fall-maharashtra-keralakarnataka-gujarat-assam-3

[53] K.E. Weick, "Sensemaking in organizations" vol.3. California, USA: Sage, 1995.

[54] T.M. Choi, Y.J. Cai, and B Shen, "Sustainable fashion supply chain management: A system of systems analysis," IEEE Transactions on Engineering Management, vol. 66, no.4, pp. 730745, Aug .2018.

[55] Y.K Dwivedi, D. Wastell, S. Laumer, H.Z. Henriksen, M.D. Myers, D. Bunker... and, S.C. Srivastava, "Research on information systems failures and successes: Status update and future directions," Information Systems Frontiers, vol. 17 no.1, pp. 143-157, Feb .2015.

[56] M.E. Porter, and J.E. Heppelmann, "How smart, connected products are transforming companies," Harvard Business Review, vol.93 , no.10, pp. 96114, Oct. 2015

[57] E. Adamides, and N. Karacapilidis, "Information technology for supporting the development and maintenance of open innovation capabilities," Journal of Innovation \& Knowledge, vol. 5, no. 1, pp. 29-38, Jan. 2020.
[58] F.D. Macías-Escrivá, R. Haber, R. Del Toro, and V. Hernandez, "Self-adaptive systems: A survey of current approaches, research challenges and applications, "Expert Systems with Applications, vol. 40, no.18, pp. 7267-7279, Dec. 2013.

[59] Sahlin, and J. Angelis, "Performance management systems: reviewing the rise of dynamics and digitalization," Cogent Business \& Management, vol. 6, no.1, pp. 1-21, Jan. 2019.

[60] C. Liew, "The future of radiology augmented with artificial intelligence: a strategy for success," European Journal of Radiology, vol. 102, pp. 152156, May. 2018.

[61] A. Majchrzak, C. Wanger, and D. Yates, "The impact of shaping on knowledge reuse for organizational improvement with wikis," MIS Quarterly, vol. 37, no. 2, pp. 455-469, June. 2013.

[62] P.C. Lee, S.H. Chen, Y.S. Lin, and H.N. Su, "Toward a Better Understanding on Technological Resilience for Sustaining Industrial Development," IEEE Transactions on Engineering Management, vol. 66, no.3, pp. 398-411, June. 2018.

[63] M. Day, "Fostering emergent resilience: the complex adaptive supply network of disaster relief," International Journal of Production Research, vol. 52, no.7, pp. 1970-1988, April. 2014.

[64] J. Paschen, J. Kietzmann, and T.C. Kietzmann, "Artificial intelligence (AI) and its implications for market knowledge in B2B marketing. Journal of Business \& Industrial Marketing, vol. 34, no. 7, pp. 1410-1419, Aug. 2019.

[65] U. Kose, and A. Arslan, "Optimization of selflearning in Computer Engineering courses: An intelligent software system supported by Artificial Neural Network and Vortex Optimization Algorithm. Computer Applications in Engineering Education, vol.25, no.1, pp.142-156, Jan. 2017.

[66] N. Achour, E. Pantzartzis, F. Pascale, and A.D. Price, "Integration of resilience and sustainability: from theory to application," International Journal of Disaster Resilience in the Built Environment, vol. 6, no.3, pp.347-362, Sep. 2015.

[67]R.Francis, and B. Bekera, "A metric and frameworks for resilience analysis of engineered and infrastructure systems. Reliability Engineering \& System Safety, vol. 121, pp. 90-103, Jan .2014.

[68] Perffers, T. Tuunanen, M.A. Rothenberge, and S. Chatterjee, "A design science research methodology for information systems research," Journal of Management Information Systems, vol. 24, no.3, pp. 45-77, Dec. 2007.

[69] T. Wu, J. Blackhurst, and P. O'grady, "Methodology for supply chain disruption analysis," International Journal of Production Research, vol.45, no.7, pp. 1665-1682, April. 2007. 
[70] H. Fan, T.C.E. Cheng, G. Li, and P.K. Lee, "The effectiveness of supply chain risk information processing capability: an information processing perspective. IEEE transactions on Engineering Management, vol.63, no.4, pp.414-425, Sept. 2016.

[71]A. Oke, D.I. Prajogo, and J. Jayaram, "Strengthening the innovation chain: The role of internal innovation climate and strategic relationships with supply chain partners," Journal of Supply Chain Management, vol.49, no. 4, pp. 4358, Oct. 2013.

[72] V. Kolbjørnsrud, R. Amico, and R.J. Thomas, "How artificial intelligence will redefine management,"Harvard Business Review, vol. 2, pp.1-6, Nov. 2016.

[73] Y. Duan, J. S. Edwards, and Y.K. Dwivedi, "Artificial intelligence for decision making in the era of Big Data-evolution, challenges and research agenda," International Journal of Information Management, vol.48, pp.63-71, Oct. 2019.

[74] M.D Kakhki, and V. B. Gargeya, "Information systems for supply chain management: a systematic literature analysis. International Journal of Production Research, vol.57, no.15-16, pp. 53185339, Jan. 2019.

[75] TCS, "From fragile to agile," Building resilience for better risk management and robust financial health, TCS, Jan. 18, 2021. [Online]. Available :https://www.tcs.com/supply-chaintransformations-resilient-fragile-to-agile

[76] Koh, G. Orzes, and F.J. Jia, "The fourth industrial revolution (Industry 4.0): technologies disruption on operations and supply chain management", International Journal of Operations \& Production Management, vol. 39, no. 6/7/8, pp., 817-828, Dec. 2019.

[77]E. Revilla and M. J. Saenz, "The impact of risk management on the frequency of supply chain disruptions: a configurational approach", International Journal of Operations \& Production Management, vol. 37, no. 5, pp. 557-576, May, 2017.

[78] Mehrotra and W. Schmidt, "The Value of Supply Chain Disruption Duration Information", Production and Operations Management, DOI: 10.1111/poms.13415, March, 2021.

[79] A. Belhadi, V. Mani, S. S. Kamble, S. A. R. Khan, and S. Verma, "Artificial intelligence-driven innovation for enhancing supply chain resilience and performance under the effect of supply chain dynamism: an empirical investigation", Annals of Operations Research, DOI: 10.1007/s10479-02103956-x, Feb, 2021.

[80] K. Katsaliaki, P. Galetsi, and S. Kumar, "Supply chain disruptions and resilience: a major review and future research agenda. Annals of Operations Research, DOI: 10.1007/s10479-020-03912-1, Jan, 2021.

[81] A. Wieland, and C. F. Durach, "Two perspectives on supply chain resilience", Journal of Business Logistics, DOI: 10.1111/jbl.12271, March, 2021.

[82] H. Y. Chen, A. Das, and D. Ivanov, "Building resilience and managing post-disruption supply chain recovery: Lessons from the information and communication technology industry", International Journal of Information Management, vol. 49, pp. 330-342, Dec, 2019.

[83] S. Papagiannidis, J. Harris, and D Morton, "WHO led the digital transformation of your company? A reflection of IT related challenges during the pandemic", International Journal of Information Management, DOI: 10.1016/j.ijinfomgt.2020.102166, Dec, 2020.

[84] M. Cavalcante, E. M. Frazzon, F. A. Forcellini, and D. Ivanov, "A supervised machine learning approach to data-driven simulation of resilient supplier selection in digital manufacturing", International Journal of Information Management, vol. 49, pp.86-97, Dec, 2019.

[85] H. Tu, Y. Du, H. Yu, A. Dubey, S. Lukic, and G. Karsai, "Resilient information architecture platform for the smart grid: A novel open-source platform for microgrid control", IEEE Transactions on Industrial Electronics, vol. 67, no.11, pp.9393-9404, Nov, 2019.

[86] R. Dubey, A. Gunasekaran, S. J. Childe, T. Papadopoulos, C. Blome, and Z. Luo, "Antecedents of resilient supply chains: An empirical study. IEEE Transactions on Engineering Management, vol. 66, no.1, pp. 8-19, July, 2017.

[87] Brink P, "Issues of reliability and validity", In: Morse J (ed) Qualitative nursing research: a contemporary dialogue. Sage, London, pp. 164186, Dec, 1991. 
Authors Biography

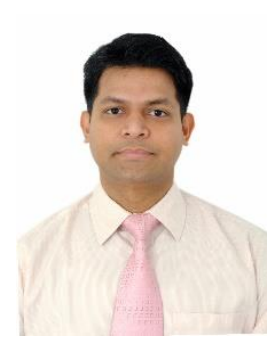

Shivam Gupta is a Professor at NEOMA Business School, France with a demonstrated history of working in the higher education industry. $\mathrm{He}$ has completed HDR from University of Montpellier, France. He has published several research papers in reputed journals and has been the recipient of the International Young Scientist Award by the National Natural Science Foundation of China (NSFC) in 2017 and winner of the 2017 Emerald South Asia LIS award.

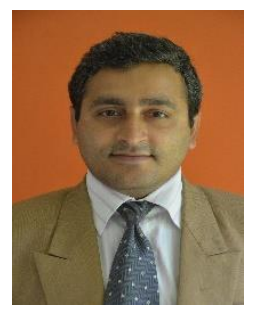

Sachin Modgil received B.Sc. degree from Himachal Pradesh University Shimla, India in 2003 and MBA (Operations Management) from Thapar Institute of Engineering and Technology (TIET), Patiala, India in 2010. He has received FPM (Ph.D.) in Technology and Operations Management from National Institute of Industrial Engineering, Mumbai, India in 2016. He is currently working as Assistant Professor in International Management Institute, Kolkata in India.

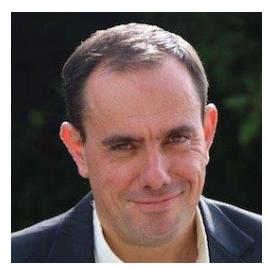

Régis Meissonier is a Professor at IAE Montpellier, University of Montpellier, France. In the past, he has been on the editorial board of reputed journals like European Journal of Information Systems, Information and Management, Systeme d'Information and Management and was the Associate Editor of MIS Quarterly Special Issue titled "Complexity and Information Systems Research in the Emerging Digital World". He has guided many PhD and HDR candidates in the past who are now affiliated with top BSchools around the world.

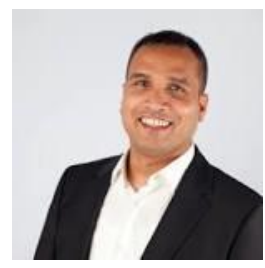

Yogesh K. Dwivedi received the M.Sc. and Ph.D. degrees in information systems from Brunel University London, Uxbridge, U.K., in 2002 and 2005, respectively. Presently he is a Professor of digital marketing and innovation with the School of Management, Swansea University. In addition, he holds a Distinguished Research Professorship at the Symbiosis Institute of Business Management (SIBM), Pune, India. Professor Dwivedi is also currently leading the International Journal of Information Management as its Editor-in-Chief. He has published more than 300 articles in a range of leading academic journals and conferences that are widely cited (more than 30000 times as per Google Scholar). He is an Associate Editor for the Journal of Business Research, European Journal of Marketing, and Government Information Quarterly. 